\title{
Conformation and Vibrational Spectroscopic Study of
}

\section{Fluorocyclohexane}

\author{
S. D. CHRISTIAN, ${ }^{a}$ J. GRUNDNES, ${ }^{b}$ P. KLABOE, ${ }^{b}$ E. TØRNENG ${ }^{b}$ and T. WOLDB $A K{ }^{b}$
}

\author{
a Department of Chemistry, University of Trondheim, NLHT, N-7000 Trondheim, Norway and \\ ${ }^{b}$ Department of Chemistry, University of Oslo, Oslo 3, Norway
}

The IR spectra of fluorocyclohexane as a vapour, liquid and as a solid at low temperatures were recorded in the region $4000-50 \mathrm{~cm}^{-1}$. High pressure IR spectra of the pure sample $(0-40 \mathrm{kbar})$ and of $\mathrm{CS}_{2}$ solutions $(0-10 \mathrm{kbar})$ in a diamond anvil cell were obtained. Raman spectra of the liquid and of the amorphous and crystalline solids at various temperatures were recorded. Fluorocyclohexane as a vapour and liquid and in the plastic solid state contained a mixture of molecules in the equatorial and axial conformations. At $c a$. $180 \mathrm{~K}$ a reversible transition between the plastic phase and an anisotropic crystal, containing the $e$-conformer took place, although a small amount of the $a$-conformer persisted in these experiments.

Compression of the liquid produced the plastic, isotropic solid at relatively low pressures $(0,5-1$ kbar), but at $c a .7 \mathrm{kbar}$ an anisotropic crystal with strongly enhanced $e$-bands was formed. The $a$-bands gradually disappeared at still higher pressure. With increased pressure, solutions of fluorocyclohexane in $\mathrm{CS}_{2}$ showed a shift in equilibrium towards the $a$-conformer. In thiourea clathrates fluorocyclohexane did not (as guest molecules) exist in a preferred conformation.

A normal coordinate analysis was performed for both conformers, using general valence force fields analogous to those for the trans-1,4-dihalocyclohexanes. Tentative assignments of the fundamental frequencies belonging to the $e$ - and $a$-conformers are presented, based upon the observed spectra and the results of the force constant calculations.

Chloro, bromo and iodocyclohexane have been studied in great detail by a variety of physical methods. In the vapour phase, in solution and in the liquid state the equatorial conformers are invariably in highest abundance, ${ }^{1}$ and the compounds all crystallize in the e-conformer at low tempera- tures $^{2-5}$ and under high pressures. ${ }^{4}$

The conformational equilibrium in fluorocyclohexane has been studied by electron diffraction, ${ }^{6}$ microwave, ${ }^{7,8} \mathrm{NMR}^{9,10}$ and ${ }^{13} \mathrm{C}$ NMR ${ }^{11,12}$ spectroscopy. The energy difference, $1080 \pm 120 \mathrm{~J} / \mathrm{mol}$ (vapour), ${ }^{8}$ is close to the value determined in solution. ${ }^{9,10}$ Therefore, the equatorial conformer is more abundant in these phases, but the axial conformer is slightly more stable relative to the equatorial form than in chloro, bromo and iodocyclohexane.

Earlier vibrational studies of fluorocyclohexane led to erroneous ${ }^{2}$ or misleading ${ }^{5}$ conclusions regarding the conformers since no simplification of the spectra was detected after solidification. This failure was probably caused by insufficient ${ }^{2}$ or too rapid ${ }^{5}$ cooling of the liquid. From analogies with the other halocyclohexanes, Rey-Lafon et al. ${ }^{5}$ attempted to attribute several IR and Raman bands to the $e$ - or $a$-conformers. More recently, they assigned the fundamentals on the basis of force constant calculations ${ }^{13}$ leading to various revisions of their earlier ${ }^{5}$ results.

We have recently made quite thorough investigations of the vibrational spectra and the conformations of various trans-1,4-dihalocyclohexanes ${ }^{14,15}$ and made normal coordinate analyses on these compounds by the overlay technique. ${ }^{16}$ The force fields are now being tested on other substituted cyclohexanes, including fluorocyclohexane. A new and thorough experimental study of the vibrational spectra of fluorocyclohexane has been performed. Particular emphasis has been placed on investigations of the low temperature and the high pressure solid phases. These studies provide important clues for the spectral interpretations. 


\section{EXPERIMENTAL}

The sample of fluorocyclohexane was prepared by adding hydrofluoric acid to cyclohexene at low temperatures,, 510 and was purified by fractionation in a spinning band column of 20 theoretical plates (m.p. $12^{\circ} \mathrm{C}$ ). Weak impurity bands first present at 720 and $648 \mathrm{~cm}^{-1}$ were not present in samples purified by further distillation, and no impurity peaks were detected by gas chromatographic analysis.

The IR spectra were recorded on a variety of instruments, including a fast scan Fourier transform spectrometer from Bruker (IFS 114c) in the region $4000-50 \mathrm{~cm}^{-1}$, a Perkin-Elmer model 225 spectrometer $\left(4000-200 \mathrm{~cm}^{-1}\right)$ and a HitachiPerkin-Elmer FIS-3 spectrometer $\left(400-100 \mathrm{~cm}^{-1}\right)$. Far IR vapour spectra were recorded with an RIIC Fourier spectrometer model 520 , equipped with a light pipe gas cell of optical path ca. $6 \mathrm{~m}$. The Raman spectra were recorded with a modified ${ }^{17}$ Cary 81 spectrometer, excited by a CRL model $52 \mathrm{G}$ argon ion laser, using the 4880 and $5145 \AA$ lines.

Conventional IR cells for vapour $(1 \mathrm{~m}$ and $10 \mathrm{~cm}$ path), liquid and solutions were employed having windows of $\mathrm{KBr}, \mathrm{CsI}$ and polyethylene. Cryostats cooled by liquid nitrogen with windows of CsI and polyethylene were used for the IR measurements, and a cooled copper plate was employed for the Raman studies. The temperatures were measured with iron-constantan thermocouples.

The high pressure solids and compressed $\mathrm{CS}_{2}$ solutions of fluorocyclohexane were studied in a diamond anvil cell with type II diamonds. In the compressed $\mathrm{CS}_{2}$ solutions the pressure was estimated by an internal standard of methanol. ${ }^{18,19}$

The various high pressure solid phases were carefully inspected with a polarization microscope. The earlier high pressure spectra were recorded with the PE-225 spectrometer. However, much better data at higher resolution and including the far IR region ${ }^{20}$ were obtained with the fast scan Fourier spectrometer due to the multiplex advantage. IR Nujol mull spectra were recorded of fluorocyclohexane - thiourea clathrates.

\section{RESULTS}

The IR spectra of fluorocyclohexane in the vapour and liquid states have been reported. ${ }^{5}$ Therefore, we have restricted our attention mostly to the solid state spectra. IR spectra of the amorphous $(90 \mathrm{~K})$, plastic $(190 \mathrm{~K})$ and anisotropic $(160 \mathrm{~K})$ solids in the region $1500-200 \mathrm{~cm}^{-1}$ are shown in Fig. 1 , whereas the detailed features in the $900-780 \mathrm{~cm}^{-1}$ region are given in Fig. 2. High pressure IR spectra of the plastic and anisotropic phases are presented
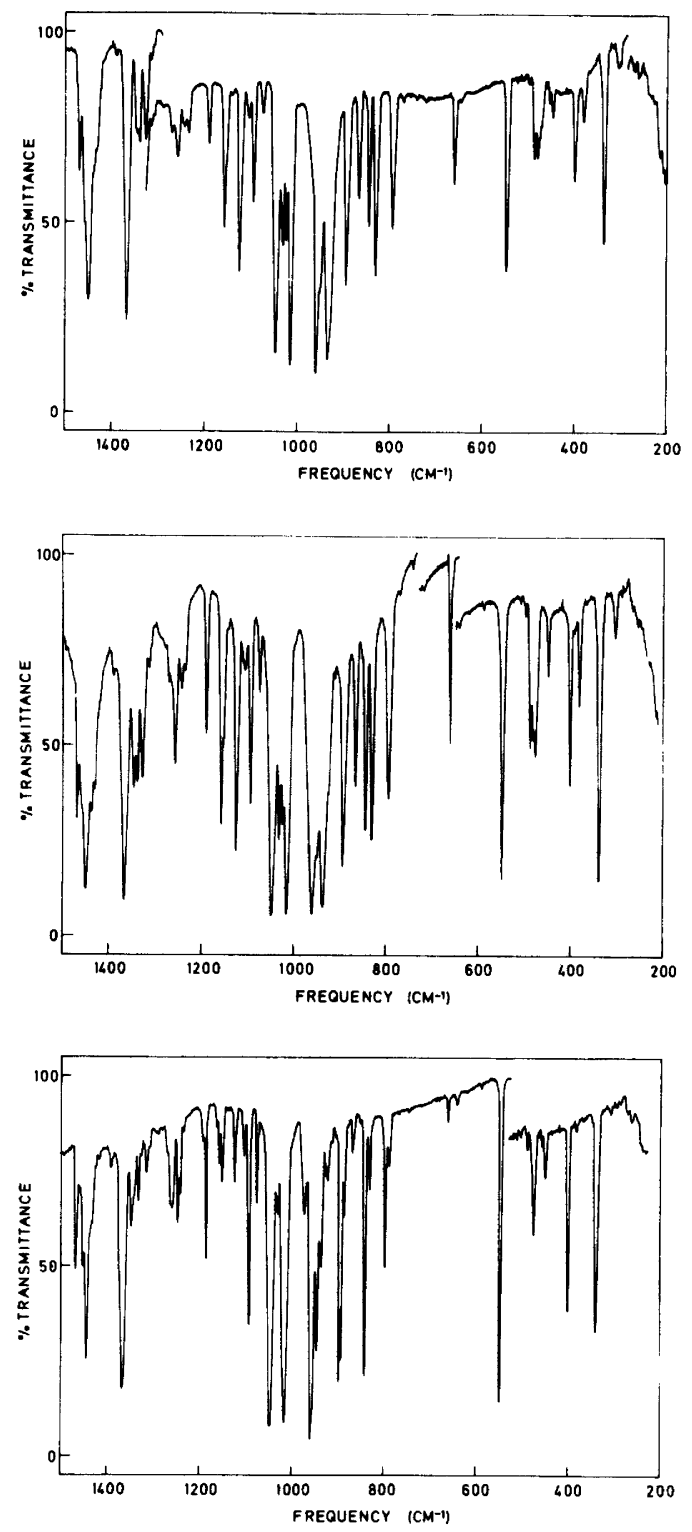

Fig. 1. Infrared spectra of fluorocyclohexane as an amorphous solid at $90 \mathrm{~K}$ (upper curve), as a plastic crystal at $190 \mathrm{~K}$ (middle curve) and as an anisotropic crystal at $160 \mathrm{~K}$ (lower curve) in the region $1500-200 \mathrm{~cm}^{-1}$

in Fig. 3, while the Raman spectra of the liquid $(296 \mathrm{~K})$ and the anisotropic solid $(90 \mathrm{~K})$ are given in Fig. 4. IR spectra of the 845 and $830 \mathrm{~cm}^{-1}$ bands at various temperatures between 170 and $183 \mathrm{~K}$ 




Fig. 2: Infrared spectra of fluorocyclohexane in the region $900-780 \mathrm{~cm}^{-1}$; solid line, amorphous solid at $90 \mathrm{~K}$; dashed line, plastic crystal at $190 \mathrm{~K}$; dashed-dotted line, anisotropic crystal at $160 \mathrm{~K}$.

are given in Fig. 5. The far-IR spectrum $(440-50$ $\mathrm{cm}^{-1}$ ) of fluorocyclohexane in cyclohexane solution is shown in Fig. 6 and spectra of the plastic and anisotropic crystals, recorded in a far-IR cryostat at $90 \mathrm{~K}$ are shown in Fig. 7. The wave numbers of the observed IR and Raman bands are listed in Table 1, but for the sake of brevity bands outside the fundamental regions $3000-2800$ and $1500-100 \mathrm{~cm}^{-1}$ are omitted.

The existence of a plastic (cubic, isotropic) crystal for fluorocyclohexane at temperatures below the melting point has been known for a long time. ${ }^{2}$ Since earlier attempts to obtain the low temperature anisotropic phase failed ${ }^{2,5}$ we report below in some detail the spectral observations at low temperatures and at high pressures.

Infrared spectra at low temperatures. When fluorocyclohexane vapour was deposited on the CsI window at $90 \mathrm{~K}$, no simplification of the spectrum occurred, an amorphous solid being formed (Fig. 1). Heating the sample promoted crystallization and the intensity of many bands was strongly reduced. When the temperature passed ca. $180 \mathrm{~K}$, however, these bands reappeared, but after slow cooling of the sample, the simplified spectrum was again recorded. Apparently the transition was observed between the plastic phase of fluorocyclohexane and the ordered, anisotropic phase in which one (or mainly one) conformer is present. The transition temperature $(180 \mathrm{~K})$ was determined with the spectrometer focused at the $830 \mathrm{~cm}^{-1}$ band, with alternative heating and cooling of the sample. With the type of cryostat used here, the temperature accuracy is supposed to be about $\pm 10 \mathrm{~K}$.

In the spectrum of the anisotropic crystals, weak residual bands persisted (Figs. 1, 2,6). The intensity of these bands was quite reproducible, and attempts to make pure "one-conformer crystals", by keeping the temperature just below the transition temperature or cycling through this temperature, were not successful. Similar observations are not uncommon in this type of experiment. We do not know, however, if this is due to incomplete conversion of the high temperature phase or to the presence of a small fraction of one conformer in the host lattice of the other.

When the plastic crystal was quenched to liquid nitrogen temperature, only small spectral changes were observed, and a conversion to anisotropic crystals did not take place at this low temperature.

Raman spectra at low temperature. In the Raman experiments the fluorocyclohexane vapour was deposited on a copper finger at $90 \mathrm{~K}$. In some cases the deposit had a glassy appearance, and attempts to promote crystallization by annealing were not successful, in contrast to what was observed with



Fig. 3. Infrared spectra of fluorocyclohexane at ambient temperature in the diamond anvil cell; solid line, ca. $40 \mathrm{kbar}$ pressure, anisotropic crystal; dashed line $c a$. 2 kbar pressure, plastic crystal; $1500-700 \mathrm{~cm}^{-1}$, res. $2 \mathrm{~cm}^{-1}, 200$ scans; $700-200 \mathrm{~cm}^{-1}$, res. $4 \mathrm{~cm}^{-1}, 500$ scans; $200-100 \mathrm{~cm}^{-1}$, res. $4 \mathrm{~cm}^{-1}, 500$ scans. 

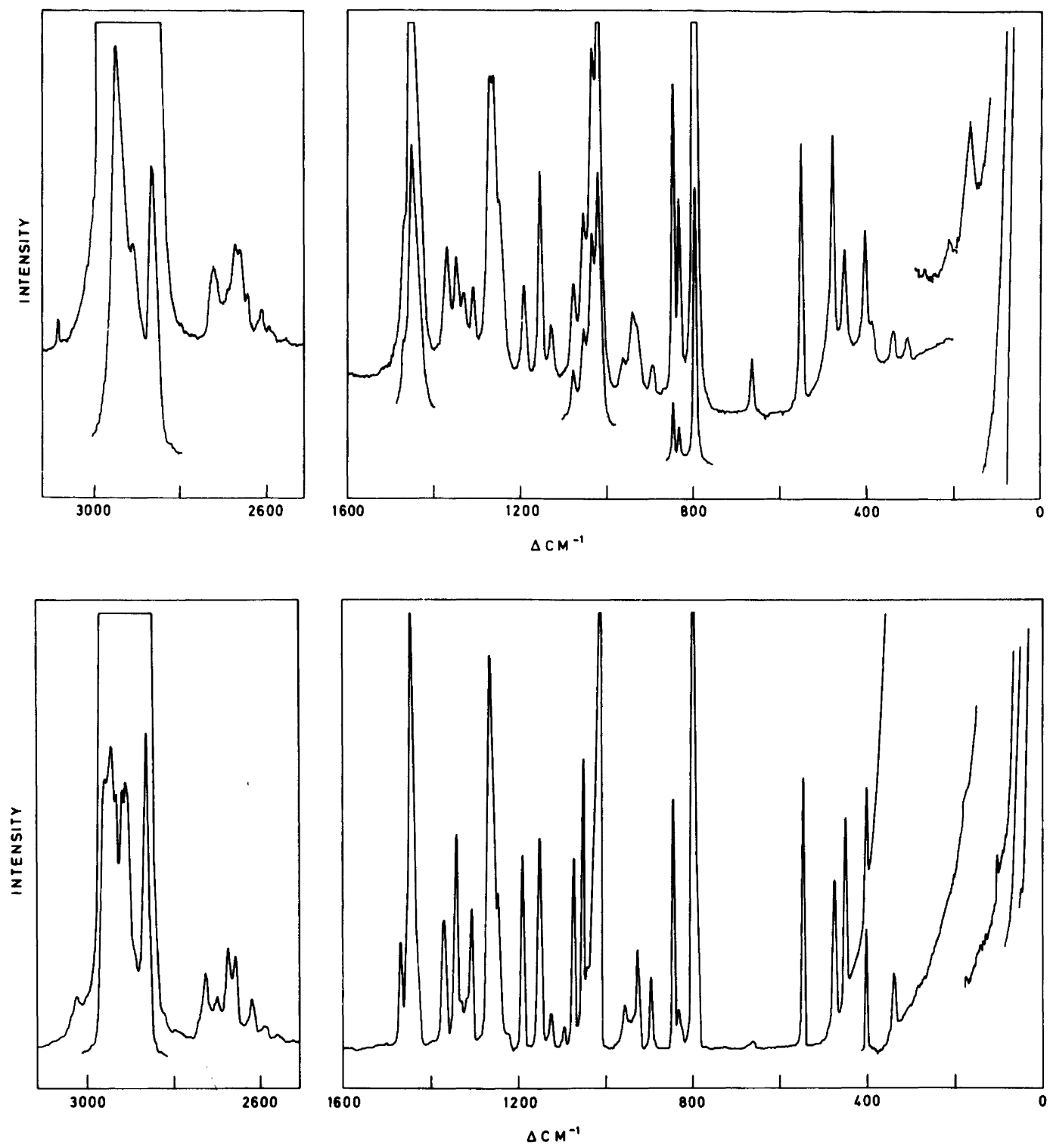

Fig. 4. Raman spectra of fluorocyclohexane as a liquid (upper curve) and as an anisotropic crystal at $90 \mathrm{~K}$ (lower curve).

the infrared cryostat. Fortunately, a frosty deposit was formed directly from the vapour in other experiments, and a simplified spectrum was recorded. Furthermore, a sharp and pronounced change in absorption took place at $c a .180 \mathrm{~K}$, and above this temperature the spectrum resembled that of the liquid. Below $180 \mathrm{~K}$ the bands which showed strongly reduced intensity corresponded with those which nearly vanished in the infrared spectrum. Undoubtedly, the phase transition from the plastic crystal to an ordered anisotropic phase was observed in these Raman experiments.

The early attempts ${ }^{2}$ to obtain anisotropic crystals of fluorocyclohexane apparently failed because 


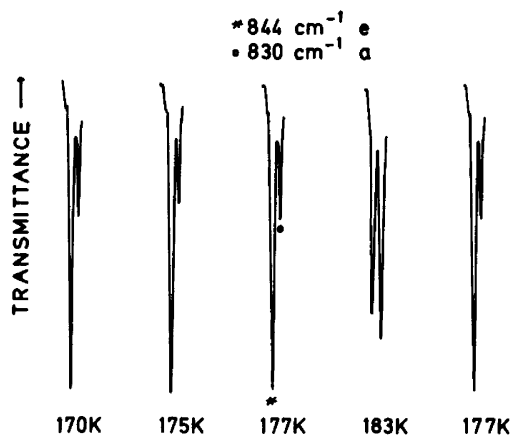

Fig. 5. The IR bands 844 and $830 \mathrm{~cm}^{-1}$ recorded at various temperatures in succession from $170 \mathrm{~K}$ to $183 \mathrm{~K}$ and back to $177 \mathrm{~K}$.

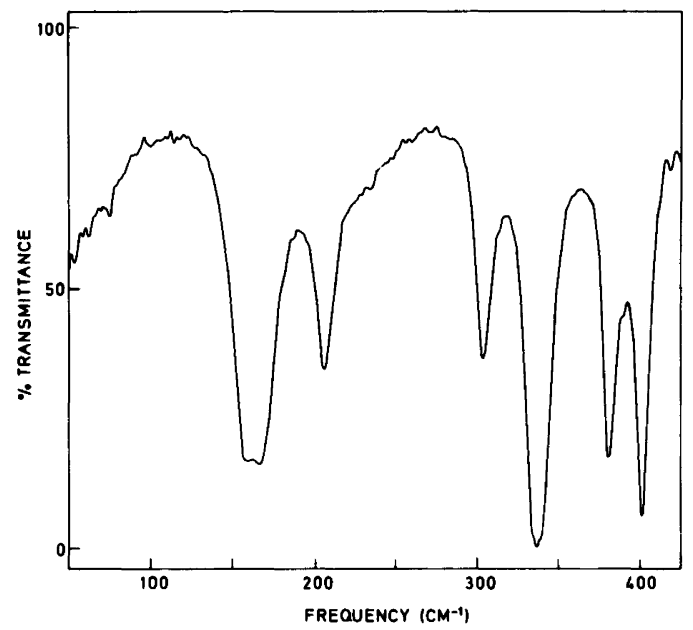

Fig. 6. Far infrared spectrum of fluorocyclohexane dissolved in cyclohexane ( $20 \%$ solution), $0.2 \mathrm{~mm}$ cell thickness, $12 \mu$ m beamsplitter, 200 scans, $2 \mathrm{~cm}^{-1}$ resolution.

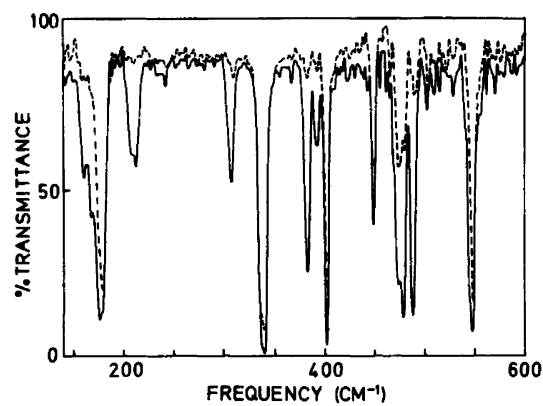

Fig. 7. Far infrared spectra of fluorocyclohexane as an amorphous solid at $90 \mathrm{~K}$ (solid line) and as an anisotropic crystal at $90 \mathrm{~K}$ (dotted line), $3.5 \mu \mathrm{m}$ beamsplitter, 280 scans, $2 \mathrm{~cm}^{-1}$ resolution. temperatures below $200 \mathrm{~K}$ were not attainable. It is not clear why the later efforts ${ }^{5}$ were unsuccessful. However, the present investigations have shown that too rapid cooling of the plastic phase may preclude detection of the "one-conformer" crystal.

From earlier experience, e.g. with halopropenes, we have concluded that compounds with conformational equilibria often crystallize more readily in a Raman than in an IR cryostat, probably because of the much thicker sample in the former. For fluorocyclohexane the situation was opposite, since we found that if amorphous solids were formed at low temperature $(90 \mathrm{~K})$ they were not converted to crystals at any available temperature. In some experiments it could be seen that an amorphous droplet formed on the cold finger simultaneously with the crystalline solid, and the laser beam could be focused on the different regions. For fluorocyclohexane, the thin layer of amorphous sample on the CsI window (IR) obviously crystallized much easier than the thick deposit on a Cu-plate employed in Raman.

Infrared spectra at high pressures. When fluorocyclohexane was compressed in the diamond anvil cell a phase transition leading to the plastic solid took place at rather low pressure. This phase change was difficult to observe under the polarization microscope and might, in fact, be overlooked. On releasing the pressure, the melting process, however, was easily observed.

We have demonstrated ${ }^{19}$ that when a gasket is used, it is not possible directly to relate pressure in the diamond anvil cell to the length of the spring which applies force to the diamond faces. Fortunately, pressure-sensitive bands of the compound under investigation can often be used to infer the actual pressure of the sample. ${ }^{19-21}$

The $865 \mathrm{~cm}^{-1}$ band in liquid fluorocyclohexane shifted less than $1 \mathrm{~cm}^{-1}$ over the range of pressures from ambient up to the pressure at which the plastic phase first appeared. A shift of this magnitude corresponds to a pressure of less than 1 kbar, probably close to $0.5 \mathrm{kbar}$. When higher pressures were applied, the phase transition between the plastic and the anisotropic phases occurred at a pressure of about $7 \mathrm{kbar}$. Inspection in the polarization microscope suggested that complete conversion had occurred from the transparent to the strongly coloured (in polarized light) anisotropic crystals. The IR spectrum of this phase was radically different from that of the plastic phase. Generally, the bands were shifted to higher wave number, as is 


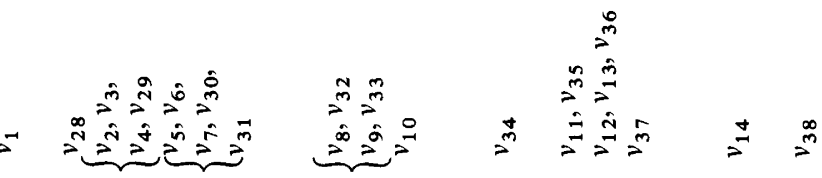



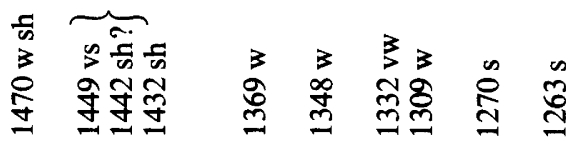

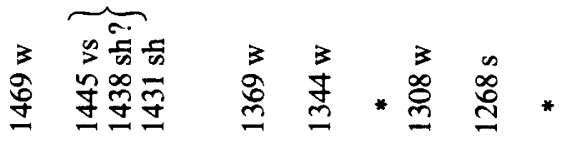



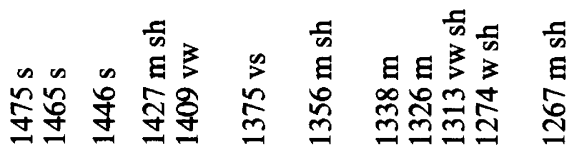

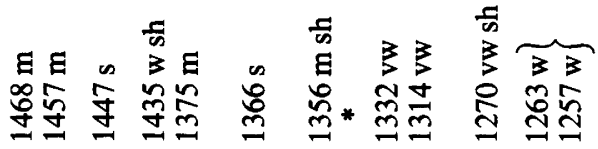

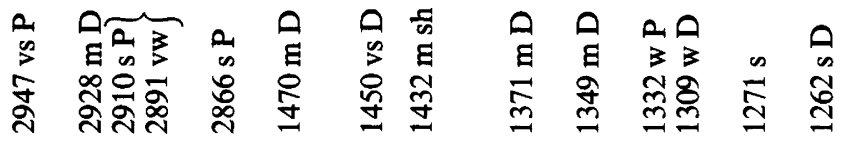

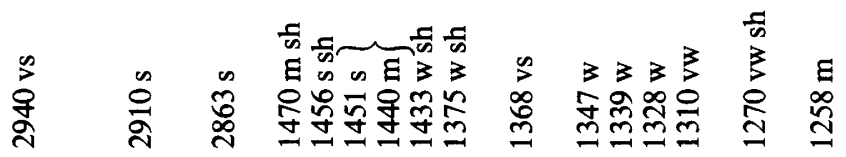

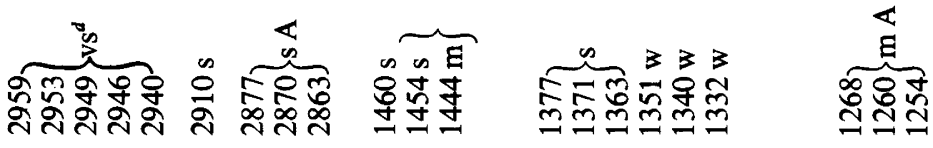




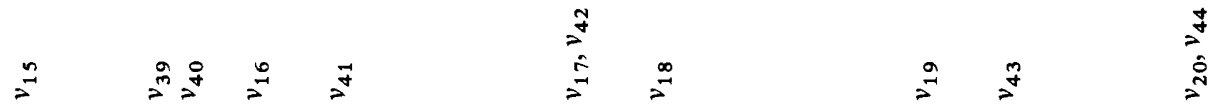

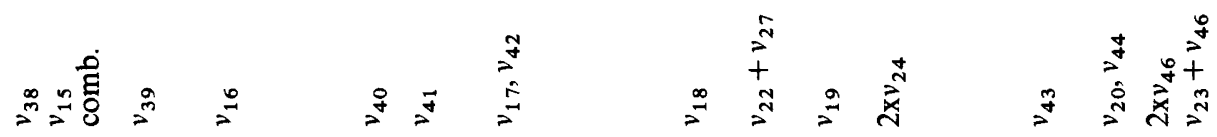

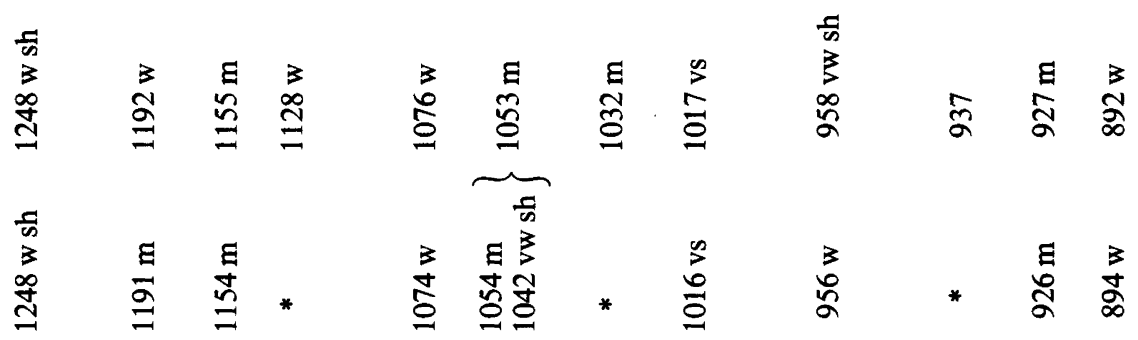

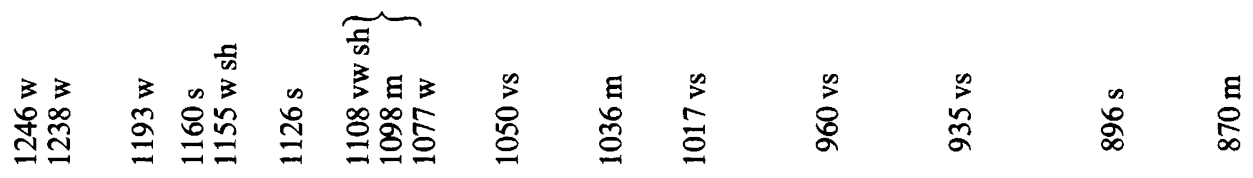

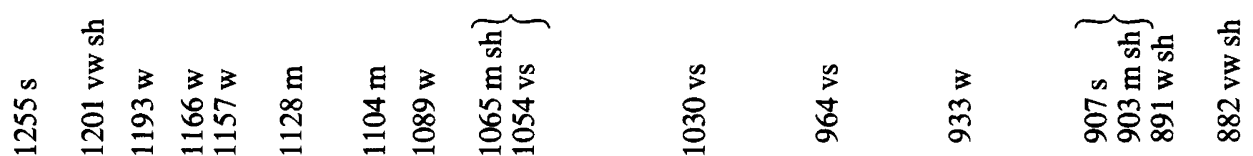

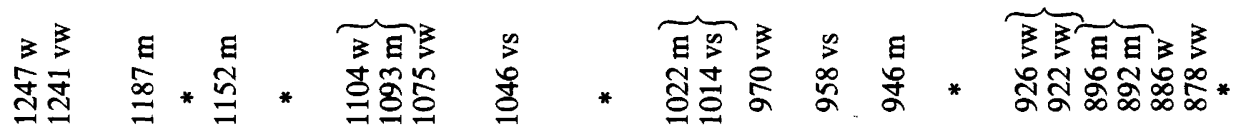

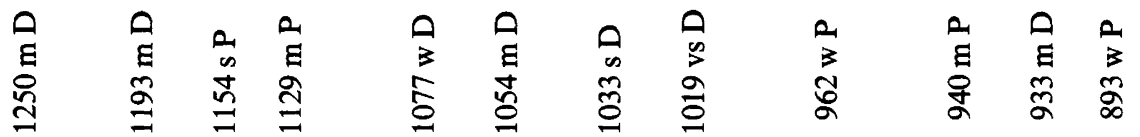

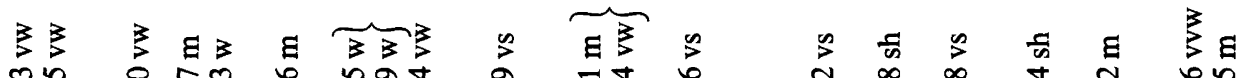

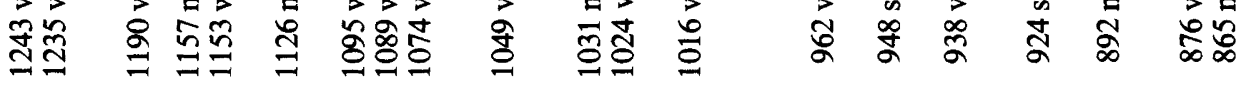

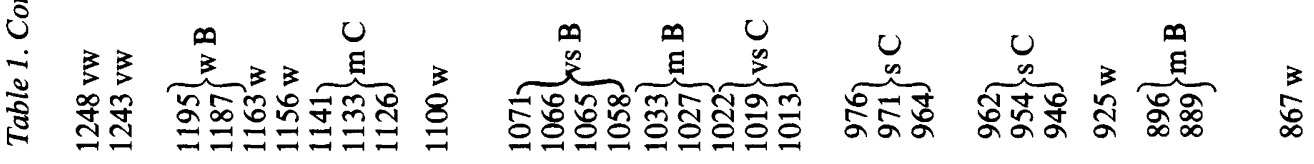
Acta Chem. Scand. A 34 (1980) No. 6 


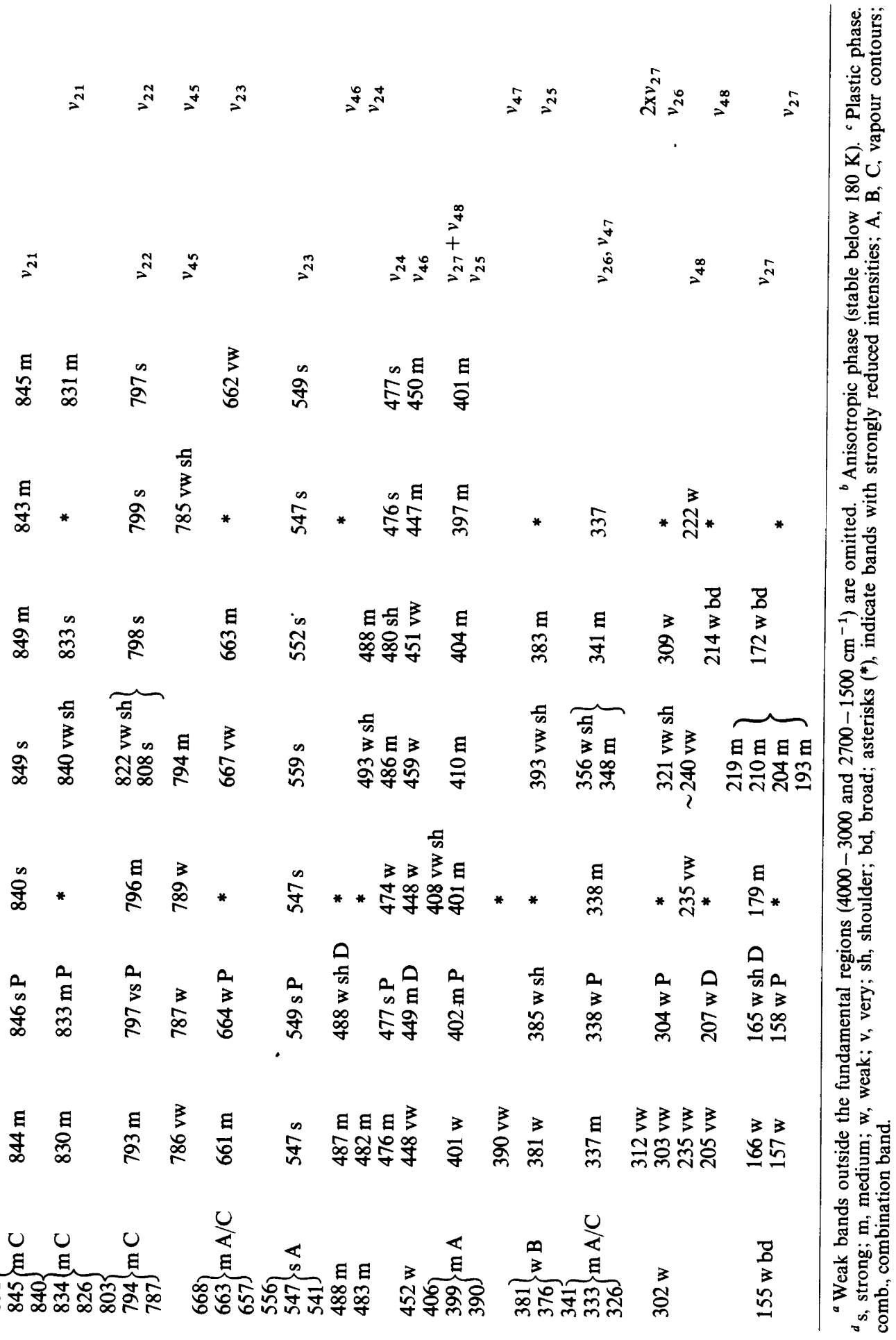


ordinarily observed at higher pressures. Most important, many bands $(381,661,830,865,1031,1126$, 1258,1328 and $1339 \mathrm{~cm}^{-1}$ ) were reduced to approximately $1 / 5$ of their former intensities.

As is apparent from Table 1, these bands are the same ones which disappeared (or were greatly reduced in intensity) in the low temperature phase below $180 \mathrm{~K}$. Undoubtedly, the high pressure anisotropic phase consists of molecules in the same conformation as the low temperature phase below 180 $\mathrm{K}$, but a somewhat larger amount of the other conformer remains than in the low temperature solid. Still higher pressures caused no changes which could be observed by microscopic inspection. However, the bands of the "impurity" conformer were gradually reduced in intensity, and at the highest pressure applied to fluorocyclohexane (estimated to be $30-40 \mathrm{kbar})$ the $303,381,830,865$ and 1031 $\mathrm{cm}^{-1}$ bands vanished. The bands at 661,1328 and $1339 \mathrm{~cm}^{-1}$ remained with very low intensities (cf. Fig. 3 and Table 1). A blue shift of the bands with increasing pressure was generally observed.

An important result of the studies at high pressure is the observation that the bands which vanish at the highest pressures (and at low temperatures below $180 \mathrm{~K}$ ) in the anisotropic solid are those which increase in intensiy as the pressure increases within the plastic phase or in $\mathrm{CS}_{2}$ solutions of fluorocyclohexane. Within the liquid or plastic phases, the conformer having the smaller partial molar volume will be favoured with increase in pressure, and the results taken together show that the conformer which has the smaller partial molar volume is not that which crystallizes out at high pressures. The $a$-conformer has the smaller volume (see below), and this means that the anisotropic crystalline phase contains molecules in the equatorial conformation, as is the case with the other halocyclohexanes. Various spectral correlations (see below) also provided supporting evidence for this conclusion.

It is surprising that a significant (and apparently reproducible) amount of the $a$-conformer remained in the anisotropic crystal at low temperatures and at moderately high pressures. A trivial explanation might be that pressure gradients in the diamond anvil cell lead to regions with lower pressure at the edges and the existence of plastic phase mixed with the anisotropic crystals. However, this is contrary to the visual observations and our experience is that nearly hydrostatic pressures are obtained within the gasket-diamond cavity also when solids are compressed. Instead we believe that domains of axial molecules are accommodated within the equatorial crystal lattice. Similar results were observed when the trans-1,4-dihalocyclohexanes were compressed and these are discussed in some detail elsewhere. ${ }^{14}$

Volume differences between the e- and the aconformers. It was reported ${ }^{18}$ that the conformational equilibrium for certain halo- and dihalocyclohexanes in $\mathrm{CS}_{2}$ solution shifts markedly in the direction of the axially substituted conformers at increased pressures. This is in agreement with larger crowding of atoms, and hence smaller volume, for the $a$ - (or $a a$ ) conformers. From the increase in the ratio of the axial to equatorial band areas with pressure, the volume change $\Delta \bar{V}$ for the conversion $e \rightarrow a$ was calculated. ${ }^{18}$ In fluorocyclohexane the bands in the $820-880 \mathrm{~cm}^{-1}$ region were well enough separated to allow measurements of band areas. It was concluded that the $830 \mathrm{~cm}^{-1}$ and 865 $\mathrm{cm}^{-1}$ bands belonged to the axial conformer, since the relative intensity of these bands increased with pressure. In contrast, the $844 \mathrm{~cm}^{-1}$ band became relatively less intense in both phases. For chlorocyclohexane the volume change for conversion of the equatorial to the axial form has been reported to be $-1.9 \pm 0.2 \mathrm{~cm}^{3} / \mathrm{mol}^{18}$ In fluorocyclohexane the variation of the ratios of band areas with pressure was smaller. From the accuracy of the data, we think it is only justified to give $-1.0 \mathrm{~cm}^{3} / \mathrm{mol}$ as the upper limit for the volume change in $\mathrm{CS}_{2}$ solution. In the plastic phase, absence of the solvent made area measurements more reliable. However, the pressure determination was somewhat more uncertain, since we had to assume the same frequency change with pressure for the $865 \mathrm{~cm}^{-1}$ band in the plastic phase as in $\mathrm{CS}_{2}$ solution. From a plot of $\ln \left(A_{830} / A_{844}\right)$ versus pressure, a value of $\Delta \bar{V}=-1.5 \pm 0.5 \mathrm{~cm}^{3} / \mathrm{mol}$ for the conversion $e \rightarrow a$ was calculated. The rather large estimated error reflects the uncertainty in the determination of the pressure.

Clathrates. In thiourea clathrates chloro- and bromocyclohexane are accomodated as $a$-conformer molecules in the channels, ${ }^{22-24}$ while iodocyclohexane ${ }^{23,24}$ has a certain amount of $e$-conformer in addition. When thiourea clathrates of fluorocyclohexane were prepared using the same techniques as described previously, ${ }^{24}$ the fluorocyclohexane bands in a Nujol mull were clearly visible in the thiourea windows $1000-800$ and $400-300$ $\mathrm{cm}^{-1}$. The intensities of the IR bands at 962,938 , 
$892,865,844,830,381,336$ and $303 \mathrm{~cm}^{-1}$ in the clathrate were compared to those in the liquid. Surprisingly, the $a$-bands were only slightly enhanced relative to the $e$-bands in the clathrate. From the band intensities of the $865(a)$ and 844 $\mathrm{cm}^{-1}(e)$ bands, the ratio $f=K_{\text {clathr }} / K_{\text {liquid }}$ (where $K_{\text {clathr. }}$ and $K_{\text {liq. }}$ are equilibrium constants $C_{\mathrm{a}} / C_{\mathrm{e}}$ in clathrate and liquid, respectively) was found to be approximately equal to 1.4 . There appears to be little enhancement of the axial conformer in fluorocyclohexane clathrate, in contrast to the behaviour of cyclohexanes with chloro-, bromo-, and pseudohalo-substituents, for which the axial conformer is highly preferred in the clathrate. (See Table 5 of Ref. 24). The fact that the axial form of fluorocyclohexanes is less favored in the clathrate probably reflects the smaller magnitude of $\Delta \bar{V}$ for the $e \rightarrow a$ conversion (in fluorocyclohexane relative to the other halocyclohexanes) and may indicate that a compressive effect analogous to mechanical pressure may be acting to stabilize particular conformers in the clathrate channels. On the other hand, axial iodocyclohexane is not so strongly favoured in the clathrate as the axial conformers of chloro- and bromocyclohexane; in the larger iodocyclohexane, the axial iodine may protrude too far into the channel walls of the clathrate to be accommodated easily.

Spectral correlations. As is apparent from Table 1, some 14 IR and Raman bands present in the vapour, liquid, solution or in the plastic crystal of fluorocyclohexane, vanished or were greatly reduced in intensity in the anisotropic crystalline solids (at low temperature and under high pressure). The number of vibrational lines remaining in the crystal below $1400 \mathrm{~cm}^{-1}$ agrees with the $\mathrm{ca} .35$ fundamentals expected for one conformer in this region. For the chloro-, bromo- and iodocyclohexanes, it has been noted that the carbon-halogen stretching band of the equatorial conformer is invariably at higher wave number than that of the axial conformer. This observation was useful in demonstrating that these halocyclohexanes crystallize in the $e$-conformer. ${ }^{2-5}$ Earlier work by Crowder and co-workers ${ }^{25} \mathrm{dem}$ onstrates that in fluorinated hydrocarbons the $\mathrm{C}-\mathrm{F}$ stretching mode is mixed with $\mathrm{CH}_{2}$ bend and $\mathrm{C}-\mathrm{C}$ stretch. The present normal coordinate analysis indicates that the 938 and $830 \mathrm{~cm}^{-1}$ bands which vanish and the 1049,1016 and $962 \mathrm{~cm}^{-1}$ bands which remain in the anisotropic crystal, all have large contributions from the $\mathrm{C}-\mathrm{F}$ stretch. Although the latter group of bands has higher wave numbers than the former, this fact alone does not provide convincing evidence that the anisotropic phase is an e-crystal.

The IR and Raman bands of halo- (and pseudohalo) cyclohexanes around $850 \mathrm{~cm}^{-1}$ fall in regular patterns, useful for spectral correlations. ${ }^{26}$ In fluorocyclohexane the vanishing bands (at 865 and 830 $\mathrm{cm}^{-1}$ ) should be assigned to the $a$-conformer and the bands remaining (at 892 and $844 \mathrm{~cm}^{-1}$ ) to the $e$-conformer for consistency with assignments in Table 2 of Ref. 26. These spectral correlations, then, support our independent conclusion from the high pressure band enhancements.

Isocyanatocyclohexane also crystallized in the $e$-conformer at low temperatures, while cyanocyclohexane apparently formed amorphous glass, with both conformers present at low temperatures. ${ }^{26}$ However, unlike the halocyclohexanes, the two latter compounds crystallized in the $a$-conformer at high pressure. $^{26}$

The assigned fundamental frequencies for the $e$ - and $a$-conformers of fluorocyclohexane are listed in Table 2 together with the calculated values. As is discussed below, the force field was transferred from the trans-1,4-dihalocyclohexanes ${ }^{16}$ with minor modifications. The agreement with the observed values should be considered very satisfactory, since the deviations are $c a .1 \%$. When the $i$ th fundamental of the $e$ - and $a$-conformers are compared, they are separated $5 \mathrm{~cm}^{-1}$ or less in 21 cases, with the separation being larger for the remaining 27 modes. Therefore, the force constant calculations support the experimental conclusion that the majority of $e$ and $a$-fundamentals falls within such a small frequency range that the bands overlap. This seems generally true for the halo- ${ }^{4,5}$ and pseudohalocyclohexanes ${ }^{26}$ while in the trans-1,4-dihalocyclohexanes ${ }^{14-16}$ spectra the bands of the two conformers are farther separated.

As is apparent from Tables 1 and 2, the $\mathrm{CH}_{2}$ stretching, scissoring and wagging modes (with the exception of the bands at 1470,1456 and $1451 \mathrm{~cm}^{-1}$ ) generally coincide for both conformers, and accidental degeneracies between $A^{\prime}$ and $A^{\prime \prime}$ modes also occur frequently. In the region below $1000 \mathrm{~cm}^{-1}$ the $e$ - and $a$-bands are often well separated, an extreme case is presented by $v_{23}$ for which the $e$ and $a$-conformer bands were observed with 114 $\mathrm{cm}^{-1}$ difference (calculated $107 \mathrm{~cm}^{-1}$ ).

In spite of the fairly complete experimental results and the force constant calculations, there are obviously uncertainties in the interpretations. The 
Table 2. Observed ${ }^{a}$ and calculated fundamental frequencies for fluorocyclohexane.

\begin{tabular}{|c|c|c|c|c|c|c|}
\hline & \multicolumn{3}{|l|}{$e$} & \multicolumn{3}{|l|}{$a$} \\
\hline & $\mathrm{PED}^{b}$ & Obs. & Calc. & PED & Obs. & Calc. \\
\hline \multicolumn{7}{|l|}{$a^{\prime}$} \\
\hline$v_{1}$ & $97 d(X)^{c}$ & 2940 & 2957 & $98 \mathrm{~d}(\mathrm{X})$ & 2940 & 2958 \\
\hline$v_{2}$ & $81 d$ & 2910 & 2922 & $95 \mathrm{~d}$ & 2910 & 2922 \\
\hline$v_{3}$ & $92 d$ & 2910 & 2916 & $96 d$ & 2910 & 2916 \\
\hline$v_{4}$ & $98 \mathrm{~d}$ & 2910 & 2914 & $97 d$ & 2910 & 2914 \\
\hline$v_{5}$ & $96 d$ & 2863 & 2857 & $94 d$ & 2863 & 2857 \\
\hline$v_{6}$ & $95 \mathrm{~d}$ & 2863 & 2853 & $96 \mathrm{~d}$ & 2863 & 2854 \\
\hline$v_{7}$ & $95 d$ & 2863 & 2851 & $96 d$ & 2863 & 2851 \\
\hline$v_{8}$ & $69 \delta+15 \gamma$ & 1456 & 1457 & $69 \delta+17 \gamma$ & 1451 & 1456 \\
\hline$v_{9}$ & $69 \delta+18 \gamma$ & 1440 & 1441 & $67 \delta+22 \gamma$ & 1440 & 1438 \\
\hline$v_{10}$ & $64 \delta+21 \gamma+10 \mathrm{R}$ & 1433 & 1427 & $71 \delta+17 \gamma$ & 1433 & 1422 \\
\hline$v_{11}$ & $36 \theta+31 \gamma+14 \mathbf{R}+12 \gamma(\mathrm{X})$ & 1368 & 1382 & $56 \theta+20 \gamma(X)+11 \gamma$ & 1347 & 1361 \\
\hline$v_{12}$ & $83 \gamma+16 \mathbf{R}$ & 1347 & 1341 & $80 \gamma+19 \mathrm{R}$ & 1339 & 1348 \\
\hline$v_{13}$ & $49 \gamma+26 \theta$ & 1328 & 1310 & $71 \gamma+10 \mathbf{R}$ & 1339 & 1342 \\
\hline$v_{14}$ & $77 \gamma+13 \mathbf{R}$ & 1270 & 1252 & $73 \gamma+19 R$ & 1270 & 1261 \\
\hline$v_{15}$ & $82 \gamma$ & 1235 & 1231 & $81 \gamma$ & 1235 & 1233 \\
\hline$v_{16}$ & $58 \gamma$ & 1153 & 1134 & $54 \gamma+19 X$ & 1126 & 1122 \\
\hline$v_{17}$ & $51 X+17 \gamma+16 \omega+14 R$ & 1049 & 1040 & $50 \mathbf{R}+32 \gamma$ & 1031 & 1031 \\
\hline$v_{18}$ & $45 R+26 \mathrm{X}+23 \gamma+10 \omega$ & 1016 & 1015 & $34 \gamma+33 \omega$ & 1016 & 1000 \\
\hline$v_{19}$ & $35 \gamma+32 \mathrm{X}+13 \mathbf{R}$ & 962 & 945 & $69 \mathrm{X}+27 \gamma+25 \mathrm{R}$ & 938 & 937 \\
\hline$v_{20}$ & $44 \gamma+41 R$ & 892 & 896 & $49 \gamma+34 \mathrm{R}$ & 865 & 857 \\
\hline$v_{21}$ & $51 \mathbf{R}+38 \gamma$ & 844 & 838 & $38 \gamma+31 \mathrm{R}+23 \mathrm{X}$ & 830 & 829 \\
\hline$v_{22}$ & $48 R+30 \gamma$ & 793 & 778 & $69 \mathrm{R}$ & 793 & 800 \\
\hline$v_{23}$ & $43 \gamma+30 \omega$ & 547 & 541 & $31 \gamma+31 \omega+11 \Xi+10 \mathbf{R}$ & 661 & 645 \\
\hline$v_{24}$ & $23 \omega+21 \Xi+21 \gamma(\mathrm{X})+16 \gamma$ & 476 & 454 & $46 \omega+32 \gamma$ & 482 & 486 \\
\hline$v_{25}$ & $59 \omega$ & 401 & 415 & $58 \omega+21 \Xi+21 \tau$ & 381 & 385 \\
\hline$v_{26}$ & $40 \omega+32 \tau_{s}$ & 337 & 339 & $38 \omega+32 \tau_{\mathrm{s}}+28 \Xi$ & 303 & 304 \\
\hline $\begin{array}{l}v_{27} \\
\mathrm{a}^{\prime \prime}\end{array}$ & $42 \tau(X)+27 \omega+14 \Xi$ & 166 & 180 & $40 \tau(\mathrm{X})+24 \omega+10 \Xi$ & 157 & 160 \\
\hline$v_{28}$ & $98 d$ & 2928 & 2918 & $97 d$ & 2928 & 2917 \\
\hline$v_{29}$ & $98 \mathrm{~d}$ & 2910 & 2913 & 98d & 2910 & 2913 \\
\hline$v_{30}$ & $96 \mathrm{~d}$ & 2863 & 2855 & $97 d$ & 2863 & 2855 \\
\hline$v_{31}$ & $97 d$ & 2863 & 2852 & $97 d$ & 2863 & 2852 \\
\hline$v_{32}$ & $59 \delta+15 \gamma+12 \mathbf{R}$ & 1470 & 1451 & $71 \delta+16 \gamma$ & 1451 & 1441 \\
\hline$v_{33}$ & $67 \delta+21 \gamma$ & 1440 & 1435 & $61 \delta+22 \gamma+12 \mathbf{R}$ & 1440 & 1435 \\
\hline$v_{34}$ & $40 \gamma+26 \mathrm{R}+23 \gamma(\mathrm{X})$ & 1375 & 1389 & $71 \gamma+21 \mathbf{R}$ & 1368 & 1368 \\
\hline$v_{35}$ & $27 \gamma+20 \mathbf{R}$ & 1368 & 1353 & $79 \gamma+13 \gamma(\mathrm{X})$ & 1347 & 1350 \\
\hline$v_{36}$ & $89 \gamma$ & 1347 & 1345 & $54 \gamma+20 \gamma(\mathrm{X})+14 \delta$ & 1339 & 1343 \\
\hline$v_{37}$ & $75 \gamma+14 \gamma(\mathrm{X})$ & 1310 & 1302 & $46 \gamma+45 \mathrm{R}+14 \gamma(\mathrm{X})$ & 1328 & 1330 \\
\hline$v_{38}$ & $73 \gamma$ & 1243 & 1245 & $77 \gamma$ & 1258 & 1259 \\
\hline$v_{39}$ & $69 \gamma+19 R$ & 1190 & 1185 & $58 \gamma+39 \mathrm{R}$ & 1157 & 1152 \\
\hline$v_{40}$ & $53 \gamma+48 \mathbf{R}$ & 1095 & 1113 & $88 \gamma+15 \gamma(\mathrm{X})$ & 1153 & 1142 \\
\hline$v_{41}$ & $71 \gamma+21 \gamma(\mathrm{X})+14 \mathrm{R}$ & 1074 & 1071 & $68 \gamma+18 \mathrm{R}$ & 1089 & 1086 \\
\hline$v_{42}$ & $57 \mathrm{R}+25 \gamma$ & 1049 & 1052 & $55 \mathrm{R}+20 \gamma$ & 1031 & 1034 \\
\hline$v_{43}$ & $49 \gamma+38 \mathbf{R}$ & 924 & 917 & $85 \gamma$ & 924 & 928 \\
\hline$v_{44}$ & $54 \gamma+25 \mathrm{R}$ & 892 & 888 & $69 \mathrm{R}+17 \gamma$ & 865 & 857 \\
\hline$v_{45}$ & $76 \gamma+14 \mathrm{R}$ & 786 & 789 & $78 \gamma+13 \mathbf{R}$ & 786 & 789 \\
\hline$v_{46}$ & $59 \omega$ & 448 & 458 & $46 \omega+30 \Xi$ & 487 & 489 \\
\hline$v_{47}$ & $78 \Xi+11 R$ & 337 & 360 & $46 \Xi+21 \omega+11 \tau$ & 390 & 387 \\
\hline$v_{48}$ & $42 \omega+42 \tau$ & 235 & 224 & $40 \omega+34 \tau$ & 205 & 197 \\
\hline
\end{tabular}

${ }^{a}$ When possible, frequency values taken from the liquid spectra are given. ${ }^{b}$ The potential energy distribution defined as $X_{\mathrm{ik}}=100 F_{\mathrm{ij}} L_{\mathrm{ik}}{ }^{2} / \lambda_{\mathrm{k}} .{ }^{c} \mathrm{~d}(\mathrm{X})$ and $\gamma(\mathrm{X}), \mathrm{C}-\mathrm{H}$ stretching and $\mathrm{CCH}$ bending in the $\mathrm{F}-\mathrm{C}-\mathrm{H}$ group; $\mathrm{d}$ and $\gamma, \mathbf{C H}$ stretchings and $\mathbf{C C H}$ bendings in the $\mathbf{C}-\mathrm{CH}_{2}$ groups; $\mathbf{R}, \mathbf{C}-\mathbf{C}$ stretchings; $\mathrm{X}, \mathrm{C}-\mathrm{F}$ stretching; $\delta$, $\mathrm{H}-\mathrm{C}-\mathrm{H}$ bendings; $\theta, \mathrm{H}-\mathrm{C}-\mathrm{F}$ bending; $\omega, \mathrm{C}-\mathrm{C}-\mathrm{C}$ bendings; $\Xi, \mathrm{C}-\mathrm{C}-\mathrm{F}$ bend; $\tau_{\mathrm{s}}$ and $\tau(\mathrm{X})$, torsions around the $\mathrm{C}_{3}-\mathrm{C}_{4}$ and the $\mathrm{C}_{1}-\mathrm{C}_{2}$ bonds $\left(F H C^{1}-\mathrm{C}^{2} \mathrm{H}_{2}-\mathrm{C}^{3} \mathrm{H}_{2}-\mathrm{C}^{4} \mathrm{H}_{2}-\mathrm{C}^{5} \mathrm{H}_{2}-\mathrm{C}^{6} \mathrm{H}_{2}\right) ; \tau$, the sum of $\tau_{\mathrm{s}}, \tau(\mathrm{X})$ and the torsion around the $\mathrm{C}_{2}-\mathrm{C}_{3}$ bond. 
Table 3. Valence force constants for fluorocyclohexane.

\begin{tabular}{|c|c|c|c|c|c|}
\hline $\begin{array}{l}\text { Force } \\
\text { constant }\end{array}$ & $\underset{n t}{\text { Group }}$ & $\begin{array}{l}\text { Coordinate(s) } \\
\text { involved }\end{array}$ & $\begin{array}{l}\text { Atoms common } \\
\text { to interacting } \\
\text { coordinates }\end{array}$ & $\begin{array}{l}\text { Calculated } \\
\text { value } \\
\phi_{\mathrm{i}}\end{array}$ & $\begin{array}{l}\text { Standard } \\
\text { error } \\
\sigma\left(\phi_{i}\right)\end{array}$ \\
\hline $\begin{array}{l}\text { Stretch }^{a} \\
K_{\mathrm{d}} \\
K_{\mathrm{d}}(\mathrm{F}) \\
K_{\mathrm{R}} \\
K_{\mathrm{R}}(\mathrm{F}) \\
K_{\mathrm{X}}\end{array}$ & $\begin{array}{l}\mathrm{C}-\mathrm{CH}_{2}-\mathrm{C} \\
\mathrm{C}-\mathrm{CHF}-\mathrm{C} \\
(\mathrm{C})-\mathrm{C}-\mathrm{C}-(\mathrm{C}) \\
\text { (C) }-\mathrm{C}-\mathrm{C}-(\mathrm{F}) \\
\mathrm{C}-\mathrm{F}\end{array}$ & $\begin{array}{l}\mathrm{C}-\mathrm{H} \\
\mathrm{C}-\mathrm{H} \\
\mathrm{C}-\mathrm{C} \\
\mathrm{C}-\mathrm{C} \\
\mathrm{C}-\mathrm{F}\end{array}$ & $\begin{array}{l}- \\
\overline{-} \\
\overline{-}\end{array}$ & $\begin{array}{l}\operatorname{mdyn} / \AA \\
(4.531)^{b} \\
(4.757) \\
(4.369) \\
4.734 \\
(5.555)\end{array}$ & 0.096 \\
\hline $\begin{array}{l}\text { Bend } \\
H_{\delta} \\
H_{\gamma}{ }^{c}\end{array}$ & $\begin{array}{l}\mathrm{C}-\mathrm{CH}_{2}-\mathrm{C} \\
\mathrm{C}-\mathrm{CH}_{2}-\mathrm{C} \\
\mathrm{C}-\mathrm{CHF}-\mathrm{C}\end{array}$ & $\begin{array}{l}\mathrm{HCH} \\
\mathrm{HCC}\end{array}$ & - & \multicolumn{2}{|l|}{$\begin{array}{l}\operatorname{mdyn} \AA / \mathrm{rad}^{2} \\
(0.5055)\end{array}$} \\
\hline $\begin{array}{l}H_{\theta} \\
H_{\omega} \\
H_{\omega}(\mathrm{F}) \\
H_{\Xi}\end{array}$ & $\begin{array}{l}\mathrm{C}-\mathrm{CHF}-\mathrm{C} \\
\mathrm{C}-\mathrm{CH}_{2}-\mathrm{C} \\
\mathrm{C}-\mathrm{CHF}-\mathrm{C} \\
\mathrm{C}-\mathrm{C}-\mathrm{F}\end{array}$ & $\begin{array}{l}\mathrm{HCF} \\
\mathrm{CCC} \\
\mathrm{CCC} \\
\mathrm{CCF}\end{array}$ & $\begin{array}{l}- \\
\overline{-} \\
-\end{array}$ & $\begin{array}{c}0.810 \\
(0.913) \\
(1.083) \\
1.083\end{array}$ & 0.051 \\
\hline $\begin{array}{l}\text { Torsion } \\
\tau \\
\tau(F)_{\mathrm{a}} \\
\tau(F)_{\mathrm{e}} \\
\tau_{\mathrm{s}}\end{array}$ & $\begin{array}{l}\mathrm{n}^{d} \\
\mathrm{CHF}-\mathrm{C}^{+} \mathrm{H}_{2}-\mathrm{C}^{*} \cdot \mathrm{H}_{2} \\
\mathrm{CHF}-\mathrm{CH}_{2} \\
\mathrm{CHF}-\mathrm{CH}_{2} \\
\mathrm{CH}_{2}-\mathrm{CH}_{2}\end{array}$ & $\begin{array}{l}\mathrm{C}^{+}-\mathrm{C}^{\neq} \\
\mathrm{C}-\mathrm{C} \\
\mathrm{C}-\mathrm{C} \\
\mathrm{C}-\mathrm{C}\end{array}$ & $\begin{array}{l}- \\
- \\
-\end{array}$ & $\begin{array}{l}\operatorname{mdyn} \AA / \mathrm{rad}^{2} \\
(0.0161) \\
0.0613 \\
0.061 \\
0.0463\end{array}$ & $\begin{array}{l}0.0066 \\
0.011 \\
0.0063\end{array}$ \\
\hline $\begin{array}{l}\text { Stretch- } \\
F_{\mathrm{d}} \\
F_{\mathrm{R}} \\
F_{\mathrm{RX}}\end{array}$ & $\begin{array}{l}\text {-stretch } \\
\mathrm{C}-\mathrm{CH}_{2}-\mathrm{C} \\
\mathrm{C}-\mathrm{C}-\mathrm{C} \\
\mathrm{C}-\mathrm{C}-\mathrm{F}\end{array}$ & $\begin{array}{l}\mathrm{C}-\mathrm{H}, \mathrm{C}-\mathrm{H} \\
\mathrm{C}-\mathrm{C}, \mathrm{C}-\mathrm{C} \\
\mathrm{C}-\mathrm{C}, \mathrm{C}-\mathrm{F}\end{array}$ & $\begin{array}{l}\mathrm{C} \\
\mathrm{C} \\
\mathrm{C}\end{array}$ & $\begin{array}{l}\operatorname{mdyn} / \AA \\
(0.019) \\
(0.296) \\
0.644\end{array}$ & 0.093 \\
\hline $\begin{array}{l}\text { Stretch-1 } \\
F_{\mathbf{R} \gamma} \\
F_{\mathbf{R} \gamma} \\
F_{\mathbf{X} \theta} \\
F_{\mathbf{R} \omega} \\
F_{\mathbf{R} \Xi} \\
F_{\mathbf{X} \Xi} \\
F_{\mathbf{X} \omega}\end{array}$ & $\begin{array}{l}\text {-bend } \\
\mathrm{C}-\mathrm{CH}_{2}-\mathrm{C} \\
\mathrm{C}-\mathrm{CH}_{2}-\mathrm{C} \\
\mathrm{C}-\mathrm{CHF}-\mathrm{C} \\
\mathrm{C}-\mathrm{C}-\mathrm{C} \\
\mathrm{C}-\mathrm{C}-\mathrm{F} \\
\mathrm{C}-\mathrm{C}-\mathrm{F} \\
\mathrm{C}-\mathrm{CH}-\mathrm{C}-\mathrm{C}\end{array}$ & $\begin{array}{l}\mathrm{C}-\mathrm{C}, \mathrm{HCC} \\
\mathrm{C}-\mathrm{C,HCC} \\
\mathrm{C}-\mathrm{F}, \mathrm{HCF} \\
\mathrm{C}-\mathrm{C}, \mathrm{CCC} \\
\mathrm{C}-\mathrm{C}, \mathrm{CCF} \\
\mathrm{C}-\mathrm{F}, \mathrm{CCF} \\
\mathrm{C}-\mathrm{F}, \mathrm{CCC}\end{array}$ & $\begin{array}{l}C-C \\
C \\
C-F \\
C-C \\
C-C \\
C-F \\
C\end{array}$ & $\begin{array}{l}\text { mdyn/rad } \\
(0.069) \\
(-0.174) \\
0.84 \\
(0.255) \\
0.049 \\
0.94 \\
-0.08\end{array}$ & $\begin{array}{l}0.11 \\
0.086 \\
0.11 \\
0.13\end{array}$ \\
\hline $\begin{array}{l}\text { Bend-be } \\
F_{y} \\
F_{y}^{\prime} \\
F_{y \theta}^{y} \\
F_{y \omega}\end{array}$ & $\begin{array}{l}\text { end } \\
\qquad \begin{array}{l}\mathrm{C}-\mathrm{CH}_{2}-\mathrm{C} \\
\mathrm{C}-\mathrm{CH}_{2}-\mathrm{C} \\
\mathrm{C}-\mathrm{CH}-\mathrm{C}-\mathrm{C} \\
\mathrm{C}-\mathrm{CH}_{2}-\mathrm{C}\end{array}\end{array}$ & $\begin{array}{l}\text { HCC,HCC } \\
\text { HCC,HCC } \\
\text { HCC,HCF } \\
\text { HCC,CCC }\end{array}$ & $\begin{array}{l}\mathrm{C}-\mathrm{C} \\
\mathrm{H}-\mathrm{C} \\
\mathrm{H}-\mathrm{C} \\
\mathrm{C}-\mathrm{C}\end{array}$ & $\begin{array}{l}\operatorname{mdyn} \AA / \mathrm{rad} \\
(-0.0227) \\
(0.0041) \\
(0) \\
(-0.090)\end{array}$ & \\
\hline $\mathbf{f}_{\gamma}$ & $-\mathrm{CH}_{2}-\mathrm{CH}_{2}-$ & $\mathrm{H}_{\mathrm{a}} \mathrm{CC}, \mathrm{H}_{\mathrm{b}} \mathrm{CC}$ & $\left(\mathrm{H}_{\mathrm{a}}\right) \mathrm{C}-\stackrel{\operatorname{trans}}{=} \mathrm{C}\left(\mathrm{H}_{\mathrm{b}}\right)$ & $(0.0735)$ & \\
\hline 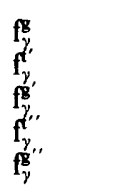 & $\begin{array}{l}-\mathrm{CH}_{2}-\mathrm{CH}_{2}- \\
-\mathrm{CH}_{2}-\mathrm{C}^{+} \mathrm{H}_{2}-\mathrm{C}^{\neq}- \\
-\mathrm{CH}_{2}-\mathrm{C}^{+} \mathrm{H}_{2}-\mathrm{C}^{\neq}- \\
\mathrm{C}^{+}-\mathrm{CH}_{2}-\mathrm{CH}_{2}-\mathrm{C}^{\neq} \\
\mathrm{C}^{+}-\mathrm{CH}_{2}-\mathrm{CH}_{2}-\mathrm{C}^{\neq}\end{array}$ & 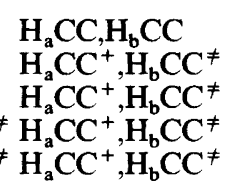 & $\begin{array}{l}\left(\mathrm{H}_{\mathrm{a}}\right) \mathrm{C} \stackrel{\text { gauche }}{\mathrm{C}}\left(\mathrm{H}_{\mathrm{b}}\right) \\
\left(\mathrm{C}-\mathrm{CH}_{\mathrm{b}}\right)-\mathrm{C}^{+}\left(\mathrm{H}_{\mathrm{a}}\right) \\
\left(\mathrm{C}-\mathrm{CH}_{\mathrm{b}}\right)-\mathrm{C}^{+}\left(\mathrm{H}_{\mathrm{a}}\right) \\
\left(\mathrm{C}-\mathrm{CH}_{\mathrm{a}}\right)-\left(\mathrm{CH}_{\mathrm{b}}-\mathrm{C}\right) \\
\left(\mathrm{C}-\mathrm{CH}_{\mathrm{a}}\right)-\left(\mathrm{CH}_{\mathrm{b}}-\mathrm{C}\right)\end{array}$ & $\begin{array}{l}(-0.0687) \\
(-0.0337) \\
(-0.0293) \\
(-0.0187) \\
(-0.0309)\end{array}$ & \\
\hline $\mathrm{f}_{\gamma \omega}^{\mathrm{t}}$ & $\mathrm{C}-\mathrm{C}-\mathrm{CH}_{2}$ & $\mathrm{HCC}, \mathrm{CCC}$ & $(\mathrm{H})-\mathrm{C} \stackrel{\text { trans }}{-} \mathrm{C}(\mathrm{C})$ & $(0.0759)$ & \\
\hline $\mathbf{f}_{y \omega}^{\mathbf{b}}$ & $\mathrm{C}-\mathrm{C}-\mathrm{CH}_{2}$ & $\mathrm{HCC}, \mathrm{CCC}$ & $(\mathrm{H})-\mathrm{C} \stackrel{\text { gauche }}{=} \mathrm{C}-(\mathrm{C})$ & $(-0.0307)$ & \\
\hline $\mathrm{f}_{\omega}^{\mathrm{z}}$ & $\mathrm{C}-\mathrm{C}-\mathrm{C}-\mathrm{C}$ & $\mathrm{CCC}, \mathrm{CCC}$ & (C) $-\mathrm{C} \stackrel{\text { gauche }}{ } \mathrm{C}-(\mathrm{C})$ & $(-0.024)$ & \\
\hline $\mathrm{f}_{\omega \Xi}^{\mathrm{g}}$ & $\mathrm{C}-\mathrm{C}-\mathrm{C}-\mathrm{F}$ & $\mathrm{CCC}, \mathrm{CCF}$ & (C) $-\mathrm{C} \stackrel{\text { gauche }}{ } \mathrm{C}-(\mathrm{F})$ & 0.035 & 0.037 \\
\hline
\end{tabular}

${ }^{a}$ Internal coordinates and symbols are defined in Refs. 16, 28. ${ }^{b}$ If a force constant is in paranthesis, its value was not adjusted in the refinement. ${ }^{c} \mathrm{H}_{\gamma}=\mathrm{H}_{\gamma}(\mathrm{F}) .{ }^{d}$ The torsion is defined as a normalized sum of three trans-torsions. 
bands which disappear from the spectrum when the pure e-conformer crystal is formed, are obviously $a$-bands. The rest of the $a$-bands coincide with the $e$-bands and cannot be determined with certainty since no spectra of the pure $a$-conformer were observed.

The IR band contours and/or Raman polarization measurements can in favourable cases determine the $A^{\prime}$ or $A^{\prime \prime}$ species, but the frequent cases of accidental degeneracy cannot be decided.

As has been done in the case of the trans-1,4dihalocyclohexanes ${ }^{14-16}$ we hope later to correlate the spectral data for the whole series of halo and pseudohalocyclohexanes.

Force constant calculations. An initial valence force field for fluorocyclohexane was constructed by transferring force constants from mono- $(\mathrm{Cl}, \mathrm{Br}$, I) and trans-1,4-dihalocyclohexanes. ${ }^{16}$ The force constants not common for all the different halocyclohexanes were given reasonable values comparable with those for n-alkyl fluorides. ${ }^{25,27}$

The molecular parameters used were the same as for the trans-1,4-dihalocyclohexanes ${ }^{16}$ except for the $\mathrm{C}-\mathrm{F}$ distance. That is, all the $\mathrm{C}-\mathrm{C}$ distances are set equal to $1.54 \AA$, the $\mathrm{C}-\mathrm{H}$ distances to 1.093 $\AA$ and all the valence angles tetrahedral. The $\mathrm{C}-\mathrm{F}$ distance $=1.398 \AA$ is the same as for the n-alkyl fluorides. ${ }^{25,27}$

The final force field is given in Table 3. The symbols are defined in Refs. 16 and 28. Only 13 force constants were adjusted during the iterations. These are the $\mathrm{C}-\mathrm{C}(\mathrm{F})$ stretching, the $\mathrm{CCF}$ and $\mathrm{HCF}$ bendings, three torsional force constants and some interaction terms involving the $\mathrm{C}-\mathrm{F}$ stretching or the CCF or HCF bendings. The other 26 force constants were fixed at the same values as for the mono- $(\mathrm{Cl}, \mathrm{Br}, \mathrm{I})$ and trans-1,4-dihalocyclohexanes. For the halogen stretching force constants a simple relationship between bond length, $r$, and force constant, $K, K r^{2}=$ constant, is found to be approximately valid. ${ }^{16,29}$ For the halocyclohexanes ${ }^{16}$ this constant was found to be $10.86 \mathrm{mdyn} \cdot \AA$ which seems to be a suitable value for fluorocyclohexane as well. Hence the $\mathrm{C}-\mathrm{F}$ stretching force constant was constrained at $10.86 / \mathrm{r}^{2}=10.86 /(1.398)^{2}$ $=5.55 \mathrm{mdyn} / \AA$.

All the final force constants are of the expected magnitude compared to those found for the n-alkyl fluorides. ${ }^{25,27}$ The torsional constant, $\tau_{\mathrm{s}}$, around the $\mathrm{C}_{1}-\mathrm{C}_{2}$ bond $\left(\mathrm{X}-\mathrm{C}-\mathrm{C}-\mathrm{C}_{1}-\mathrm{C}_{2}-\mathrm{C}-\mathrm{C}\right)$ is found to be $0.046 \mathrm{mdyn} \AA / \mathrm{rad}^{2}$. For chloro-, bromo- and iodocyclohexane as well as for cyclohexane a force constant of $c a .0 .04 \mathrm{mdyn} \AA / \mathrm{rad}^{2}$ will give a much better fit of the lowest vibrational frequencies than obtained in calculations ${ }^{28,30,31}$ where a force constant of $0.024 \mathrm{mdyn} \AA / \mathrm{rad}^{2}$ was used.

The observed and calculated frequencies are given in Table 2 . The agreement is very good considering the approximations used.

Acknowledgement. Financial support from the Norwegian Research Council for Science and the Humanities is acknowledged.

\section{REFERENCES}

1. Eliel, E. L., Allinger, N. L., Angyal, S. J. and Morrison, G. A. Conformational Analysis, Interscience, New York.1966.

2. Klæboe, P., Lothe, J. J. and Lunde, K. Acta Chem. Scand. 10 (1956) 1465.

3. Remizov, A. B. and Sverdlov, L. M. Izv. Vyssh. Uchebn. Zaved. Fiz. 11 (1968) 150.

4. Klæboe, P. Acta Chem. Scand. 23 (1969) 2641.

5. Rey-Lafon, M., Rouffi, C., Camiade, M. and Forel, M. T. J. Chim. Phys. 67 (1970) 2030.

6. Andersen, P. Acta Chem. Scand. 16 (1962) 2337.

7. Pierce, L. and Nelson, R. J. Am. Chem. Soc. 88 (1966) 216.

8. Sharpen, L. H. J. Am. Chem. Soc. 94 (1972) 3737.

9. Eliel, E. L. and Martin, J. R. L. J. Am. Chem. Soc. 90 (1968) 689.

10. Jensen, F. R., Bushweller, C. H. and Beck, B. H. J. Am. Chem. Soc. 91 (1969) 344.

11. Schneider, H. J. and Hopper, V. Tetrahedron Lett. 7 (1974) 579.

12. Subbotin, O. A. and Sergeyev, N. M. J. Am. Chem. Soc. 97 (1975) 1080.

13. Rey-Lafon, M. and Forel, M. T. J. Mol. Struct. 29 (1975) 193.

14. Woldbæk, T., Ellestad, O. H., Gustavsen, J. E. and Klæboe, P. J. Mol. Struct. 62 (1980) 9.

15. Woldbæk, T. and Klæboe, P. J. Mol. Struct. 63 (1980) 195.

16. Woldbæk, T., Nielsen, C. J. and Klæboe, P. J. Mol. Struct. In press.

17. Gilbert, B. and Duyckaerts, G. Spectrochim. Acta Part A 26 (1970) 2197.

18. Christian, S. D., Grundnes, J. and Klæboe, P. J. Am. Chem. Soc. 97 (1975) 3864.

19. Christian, S. D., Grundnes, J. and Klæboe, P. Appl. Spectrosc. 30 (1976) 227.

20. Klæboe, P. and Woldbæk, T. Appl. Spectrosc. 32 (1978) 588.

21. Christian, S. D., Grundnes, J. and Klæboe, P. J. Chem. Phys. 65 (1976) 496.

22. Fukushima, K. J. Mol. Struct. 34 (1976) 67. 
23. Allen, A., Fawcett, V. and Long, D. A. J. Raman Spectrosc. 4 (1976) 285.

24. Gustavsen, J. E., Klæboe, P. and Kvila, H. Acta Chem. Scand. A 32 (1978) 25.

25. Crowder, G. A. and Mao, H. K. J. Mol. Struct. 18 (1973) 33.

26. Horntvedt, H. and Klæboe, P. Acta Chem. Scand. A 29 (1975) 528.

27. Crowder, G. A. and Mao, H. K. J. Mol. Struct. 23 (1974) 161.

28. Snyder, R. G. and Schachtschneider, J. H. Spectrochim. Acta 21 (1965) 169.

29. Bjørklund, S., Augdahl, E., Christensen, D. H. and Sørensen, G. O. Spectrochim. Acta Part A 32 (1976) 1021.

30. Snyder, R. G. and Schachtschneider, J. H. J. Mol. Spectrosc. 30 (1969) 290.

31. Wiberg, K. B. and Shrake, A. Spectrochim. Acta Part A 29 (1973) 583.

Received February 26, 1980. 